\title{
A generative model of the crab cardiac neuromuscular system with modulation
}

\author{
Estee Stern ${ }^{1 *}$, Keyla García-Crescioni ${ }^{2}$, Mark W Miller ${ }^{2}$, Charles S Peskin $^{3}$, Vladimir Brezina ${ }^{1}$ \\ From Twentieth Annual Computational Neuroscience Meeting: CNS*2011 \\ Stockholm, Sweden. 23-28 July 2011
}

The neurogenic crab heart is driven by the cardiac ganglion (CG), a central pattern generator that is embedded within the heart itself. The CG and the heart muscle form a complete closed-loop neuromuscular system. The bursting spike pattern generated by the CG drives the contractions of the muscle. These contractions, as well as previous spiking, then modify future spike generation. The system is extensively regulated by numerous neuromodulators. Here, we present a model of the complete system, with and without modulation.

We have modeled the system, at the level of spikes and contractions, as three processes: (1) the production of the contractions by the CG spikes, (2) the dependence of the CG spikes on the contractions, and (3) the dependence of the CG spikes on their own history. Using a system-identification method that we have developed [1], we first characterized each process separately from experimental data collected in the blue crab, Callinectes sapidus. Process (1) was characterized from spike-elicited contraction data in terms of three functions: $K$, the single-spike contraction kernel, $H$, a history kernel, and $F$, a static nonlinear function. These three functions successfully predict the contraction response to arbitrary spike trains. Using a modified version of the same method, we then characterized processes (2) and (3) together from data in which the CG spike pattern was recorded in response to stretches of the muscle. This gave three additional functions: $K$ ', a kernel describing the effect of muscle length change on the generation of CG spikes, $H^{\prime}$, a kernel describing the effect of a CG spike on the generation of future CG spikes, and $F^{\prime}$, another static nonlinear function. Finally, we repeated all of these steps using data collected in the

\footnotetext{
* Correspondence: estee.stern@mssm.edu

'Department of Neuroscience, Mount Sinai School of Medicine, New York, NY, USA

Full list of author information is available at the end of the article
}

presence of modulators to find, in each case, six modified kernel functions.

Combining the six unmodulated, or modulated, functions then gave a generative model of the complete cardiac system. This model exhibits a number of modes of spike generation, and resulting contraction, including multiple bursting modes, tonic firing, and no firing. It is likely that the modulators take the system from one mode to another. An example of a modeled shift induced by the addition of a modulator is shown in Fig.

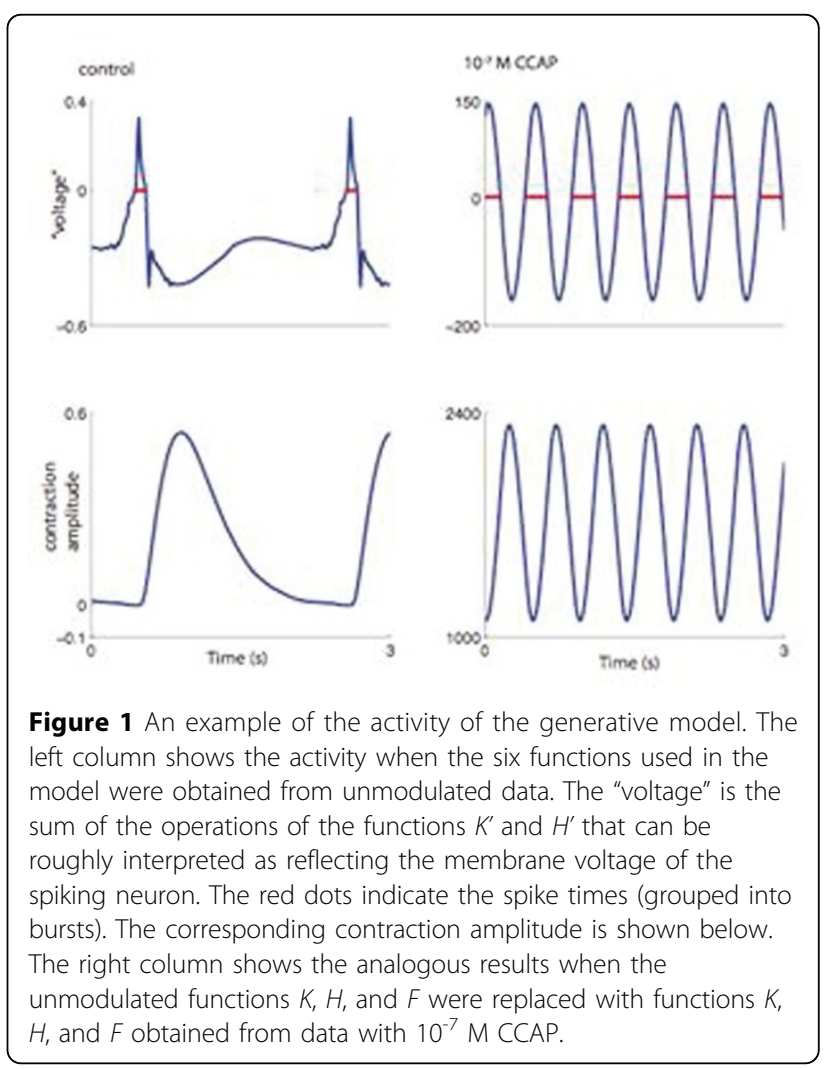


1, where the addition of crustacean cardioactive peptide (CCAP) shortens the cycle period by $\sim 75 \%$. The model can be used to better understand the global actions of the modulators and how their multiple actions allow the cardiac system to respond to physiological demands in a robust, yet flexible manner.

\section{Acknowledgements}

Supported by NS058017, NS41497, GM08224.

\section{Author details}

'Department of Neuroscience, Mount Sinai School of Medicine, New York, NY, USA. ${ }^{2}$ Institute of Neurobiology, University of Puerto Rico Medical Sciences Campus, San Juan, PR, USA. ${ }^{3}$ Courant Institute of Mathematical Sciences and Center for Neural Science, New York University, New York, NY, USA.

Published: 18 July 2011

\section{Reference}

1. Stern E, Garcia-Crescioni K, Miller MW, Peskin CS, Brezina V: A Method for decoding the neuromuscular spike-response transform. J Neurosci Methods 2009, 184:337-356.

doi:10.1186/1471-2202-12-S1-P22

Cite this article as: Stern et al:: A generative model of the crab cardiac neuromuscular system with modulation. BMC Neuroscience 2011 12(Suppl 1):P22.

\section{Submit your next manuscript to BioMed Central} and take full advantage of:

- Convenient online submission

- Thorough peer review

- No space constraints or color figure charges

- Immediate publication on acceptance

- Inclusion in PubMed, CAS, Scopus and Google Scholar

- Research which is freely available for redistribution 